\title{
APROPRIAÇÃO SOCIAL DAS TICS: CIDADANIA E INCLUSÃO SOCIODIGITAL COM O PROGRAMA GESAC
}

Social appropriation of ICTs: sociodigital inclusion and citizenship with Gesac program

Carlos Roberto Massao Hayashi

Vinícius Wagner Oliveira Santos

\begin{abstract}
Resumo
O Governo Eletrônico - Serviço de Atendimento ao Cidadão (Gesac) é um projeto do governo federal que tem como responsável o Ministério das Comunicações (MC) e visa proporcionar a infraestrutura tecnológica necessária para a implantação de Telecentros comunitários, além de fazer interface com uma gama de outros projetos os quais auxilia. Dessa forma, o programa gerencia uma série de iniciativas de inclusão sociodigital por todo o Brasil. Este artigo procura discutir pontos importantes sobre o Gesac, entendendo que este projeto procura se aproximar da sociedade, com a implantação de serviços que deem condições plenas no exercício da cidadania, através da apropriação social das TICs.
\end{abstract}

Palavras-chave: Apropriação Social. Cidadania. Inclusão social. Inclusão digital. Gesac.

\begin{abstract}
The Electronic Government - Customer Service for Citizens (Gesac) is a federal government project subordinated to the Ministry of Communications (MC). Gesac aims to provide the necessary technological infrastructure for the implementation of Community Telecenters, in addition to interface with a range of other dependent projects. Thus, the program manages series of initiatives for sociodigital inclusion throughout Brazil. This article discusses important points about Gesac, understanding that the project seeks to approach society with the deployment of services that provide full conditions in the exercise of citizenship through the social appropriation of ICTs.
\end{abstract}

Keywords: Social appropriation. Citizenship. Social inclusion. Digital inclusion. Gesac. 


\title{
Introdução
}

O Governo Eletrônico - Serviço de Atendimento ao Cidadão (Gesac) surpreendeu e superou muitas expectativas no cenário de expansão do acesso às Tecnologias de Informação e Comunicação (TICs) em todo o território nacional. De acordo com divulgação feita pelo Ministério das Comunicações em dezembro de 2008, dos 5565 municípios do país, 5354 deles já haviam recebido, até então, pelo menos um "kit telecentro".

\begin{abstract}
Eles contêm um servidor de informática, 10 computadores, 01 central de monitoramento com uma câmera de vídeo de segurança, um roteador wireless, 11 estabilizadores, uma impressora a laser, um projetor multimídia (datashow), 21 cadeiras, uma mesa do professor, 11 mesas para computador, uma mesa para impressora e um armário baixo. Os telecentros são conectados à Internet de alta velocidade e contam com os serviços de telefonia, via VolP e IPTV, que permitem a veiculação de programas como a TV Escola, por exemplo. (REVISTA DO MINISTÉRIO DAS COMUNICAÇÕES, 2008)
\end{abstract}

Próximo de atingir $100 \%$ de abrangência no que tange à expansão da infraestrutura em municípios do país, o Ministério concentra seus esforços em incluir as 211 cidades ainda faltantes na lista, além de fazer alguns ajustes pendentes no que diz respeito à capacitação de pessoal e à efetiva funcionalidade de todos os "Pontos de Presença", como são chamados os locais com equipamento receptor do sinal do Gesac em funcionamento.

Para situarmos a proposta do Gesac é importante contextualizar a inclusão sociodigital no Brasil. É perceptível que a exclusão sociodigital é muito extensa, necessitando de políticas públicas urgentes voltadas para a melhoria desse quadro. O governo federal tem cerca de 20 programas de inclusão digital, cada um com suas próprias especificidades, além dos programas estaduais e municipais em vários locais do país. Este quadro pode ser incrementado por meio da ampliação dos programas e do efetivo acesso, em uma tentativa de universalização dos serviços.

Para entendermos melhor esse cenário, necessitamos compreender alguns conceitos que estão intimamente ligados ao contexto da inclusão sociodigital no Brasil, sendo que o principal deles é o de apropriação social da tecnologia, que é o que realmente faz a grande diferença na vida das pessoas. 
É nesse contexto que este artigo, de caráter crítico-reflexivo, procura descrever e discutir pontos importantes sobre o Gesac, entendendo que este projeto procura se aproximar da sociedade, com a implantação de serviços que deem condições plenas no exercício da cidadania, pela apropriação social das TICs. Em termos metodológicos, trata-se de uma abordagem analítico-descritiva que utilizou como fonte de dados textos oficiais do Gesac, disponíveis online. Para problematizar o impacto do Gesac na sociedade recorreu-se ainda a autores que refletiram sobre conceitos chave nos campos das tecnologias de informação e comunicação e dos estudos sociais da ciência e da tecnologia.

\section{Sociedade da Informação}

A inclusão digital, obrigatoriamente nos leva também a tratar de outros temas, como cidadania digital, apropriação e inclusão social, todos inseridos no contexto da sociedade da informação.

No final da década de 1990, ganhou força no país um movimento em prol da sociedade da informação, que pode ser definida como a

$$
\begin{aligned}
& \text { sociedade que recorre predominantemente às tecnologias da } \\
& \text { informação e comunicação para a troca de informação em } \\
& \text { formato digital, suportando a interação entre indivíduos e entre } \\
& \text { estes e instituições, recorrendo a práticas e métodos em } \\
& \text { construção permanente. (NAZARENO et. al., 2006, p.13) }
\end{aligned}
$$

Alinhado às mudanças e novas demandas mundiais, surge no país o programa Soclnfo - Sociedade da Informação no Brasil, em 1999, com suas bases amparadas pelo Ministério da Ciência e Tecnologia (MCT). Ele visava formular e implementar políticas públicas para que o país pudesse adquirir competência informacional nas diversas esferas sociais, obtendo conhecimento e domínio sobre as TICs e utilizando-as para um adequado gerenciamento de grandes volumes de informação para estabelecer uma conexão sólida com o resto do mundo.

Para alavancar esse processo, o ministério, em parceria com outros órgãos, lançou, no ano 2000, o Livro Verde da Sociedade da Informação 
no Brasil, obra que reunia propostas, discussões, problemáticas, prognósticos e demais informações úteis e necessárias à consolidação de uma verdadeira sociedade da informação no país, e que até hoje é uma das principais referências sobre o assunto.

O Livro Verde traz discussões muito importantes sobre a temática em questão. Uma de suas metas era servir de base informativa para um amplo processo de participação da sociedade nas decisões que culminariam com o lançamento de uma outra obra, um "Livro Branco", que conteria um detalhado agendamento das políticas públicas para o setor, a serem implementadas nos anos subsequentes.

\begin{abstract}
O objetivo do Programa Sociedade da Informação é integrar, coordenar e fomentar ações para a utilização de tecnologias de informação e comunicação, de forma a contribuir para a inclusão social de todos os brasileiros na nova sociedade e, ao mesmo tempo, contribuir para que a economia do País tenha condições de competir no mercado global. A execução do Programa pressupõe o compartilhamento de responsabilidades entre os três setores: governo, iniciativa privada e sociedade civil. (TAKAHASHI, 2000, p.10)
\end{abstract}

Dessa forma, esse novo contexto traz consigo novas demandas, necessárias ao bom andamento do processo em vigor. A inclusão digital e o maior acesso às novas TICs por parte da população tornam-se requisitos para o desenvolvimento e expansão da sociedade da informação no Brasil, com a promessa de que isso traria inclusão social e melhorias para a economia nacional.

\title{
Tecnologias da Informação e Comunicação e Inclusão Sociodigital
}

Nesse contexto da Sociedade da Informação, acabamos por agregar um termo que se torna parte integrante e permanente de toda e qualquer discussão relacionada a esse tema - as TICs, representantes mais populares da "explosiva" e constante evolução tecnológica que vimos presenciando, principalmente nos últimos dez anos. Quanto a isso, estamos falando fundamentalmente dos computadores e da Internet, os grandes 
responsáveis pela expansão exorbitante da interconexão dos processos comunicativos em nível mundial, por intermédio da rede mundial de computadores e seu potencial de funcionamento "all/full time", deixando pessoas em contato 24 horas por dia.

De posse dessas informações, podemos tratar o domínio das TICs como sendo requisito para todo e qualquer programa de inclusão sociodigital. Ainda, o termo sociodigital torna-se algo bem natural para o contexto nacional, pois o Brasil vive uma exclusão não só digital, mas também e, principalmente, social, sendo que as iniciativas de inclusão digital no país são pensadas com o objetivo primeiro de promoção da inclusão social, por isso, nada mais coerente do que fundir os dois termos em um. Segundo Takahashi (2000, p. 7), "no novo paradigma, a universalização dos serviços de informação e comunicação é condição necessária, ainda que não suficiente, para a inserção dos indivíduos como cidadãos".

É necessário que os programas de inclusão ampliem o acesso a essas ferramentas e promovam um processo de educação tecnológica no que diz respeito a esses recursos, abrangendo uso básico e avançado, de acordo com as necessidades específicas e reais possibilidades do programa de inclusão digital em questão, podendo ir além, pois

$$
\begin{aligned}
& \text { entende-se, como ponto de partida do conceito de inclusão } \\
& \text { digital, o acesso à informação que está nos meios digitais e, } \\
& \text { como ponto de chegada, a assimilação da informação e sua } \\
& \text { reelaboração em novo conhecimento, tendo como } \\
& \text { consequência desejável a melhoria da qualidade de vida das } \\
& \text { pessoas. (SILVA et al., 2005, p. 30) }
\end{aligned}
$$

Não podemos esquecer das TICs, que são apenas as "ferramentas", não devendo superar os próprios usuários no quesito importância. Isso precisa ser ressaltado devido ao fato de que muitas iniciativas de educação tecnológica acabam por centrar atenções e esforços nas ferramentas, deixando de lado as pessoas, que deveriam ser os principais personagens do processo. 


\title{
Alfabetização, letramento, cidadania e "fluência" digital
}

Segundo Nazareno, a inclusão digital é o

\begin{abstract}
processo de alfabetização tecnológica e acesso a recursos tecnológicos, no qual estão inclusas as iniciativas para a divulgação da Sociedade da Informação entre as classes menos favorecidas, impulsionadas tanto pelo governo como por iniciativas de caráter não governamental. (NAZARENO et. al, 2006, p.14)
\end{abstract}

O grande problema encontrado quando trabalhamos com inclusão digital consiste na escolha de alguns termos a serem usados, que sempre são motivos de impasses e divergências dentre a gama de pesquisadores que realizam estudos na área.

Existem aqueles que afirmam que na inclusão digital deve haver um processo de "Alfabetização Digital". Carvalho e Carvalho citam Rondelli para definir alfabetização digital como: "a aprendizagem necessária ao indivíduo para circular e interagir no mundo das mídias digitais como consumidor e como produtor de seus conteúdos e processos" (CARVALHO e CARVALHO, 2007, p.3).

Já outros estudiosos preferem que, ao invés de alfabetização digital, seja usado o termo "Letramento Digital" que: "seria a habilidade para construir sentido, capacidade para localizar, filtrar e avaliar criticamente informação eletrônica, estando essa em palavras, elementos pictóricos, sonoros ou qualquer outro" (SILVA et al., 2005, p.33).

Ainda há outra corrente, a americana (o Comitê de Alfabetização em Tecnologias de Informatização - Committee of Information Technology Literacy) que tenta modificar o uso do termo não usando nem alfabetização, nem letramento, mas "fluência", entendida como a "capacidade de reformular conhecimentos, expressar-se criativa e apropriadamente, bem como produzir e gerar informação (em vez de meramente compreendê-la)" (TAKAHASHI, 2000, p.49).

Portanto, nesse contexto, torna-se bastante complexo fazer uma escolha sobre qual termo usar, qual é mais pertinente e qual é mais errado. Acreditamos que o ponto principal nessa questão está calcado nas 
características básicas que um programa de inclusão digital deve conter, para identificá-las em conjunto e defini-las. Dessa forma, um programa de inclusão digital, primeiramente, deve ser um programa de inclusão sociodigital, de acordo com o que já foi discutido anteriormente.

Selecionadas as características, um programa dessa natureza deveria oferecer um treinamento tecnológico básico unido a um processo instrucional abordando a história e teoria sobre as ferramentas utilizadas. Em seguida (ou concomitantemente), viria uma tentativa de construção de significados, no que tange ao papel social e à importância desse processo pelo qual essa pessoa está passando. Em aulas dessa natureza, a pessoa deve adquirir conhecimento e capacidade para acessar, gerenciar, compreender, ressignificar e também produzir informação, aplicando todo esse processo ao seu cotidiano e contexto social de forma positiva para sua vida e também para a vida de outras pessoas.

Acreditamos que essa seria uma forma interessante de unir os diferentes conceitos a fim de criar um mais completo, apesar de um pouco mais complexo. Mesmo assim, isso não seria suficiente. Para olhos desavisados, uma iniciativa de inclusão digital seria basicamente fornecer acesso a um computador com Internet para uma pessoa que não o tem e, no máximo, dar-lhe um ensinamento básico de como utilizar essa ferramenta. Sobre o uso do termo "inclusão", para Buzato:

\footnotetext{
Tomar a palavra inclusão como forma de delimitar o tema deste trabalho não foi uma decisão fácil. Necessito fazê-lo porque se trata do termo mais utilizado hoje para descrever um objetivo ou ideal que expressões como cidadania, dignidade ou justiça social talvez descrevessem melhor, se não estivessem desgastadas pela hipocrisia do nosso dia-a-dia. Utilizar inclusão, portanto, dá a possibilidade de obter mais interlocutores; por isso o fiz. (BUZATO, 2008, p. 325)
}

Apesar de parecer simples, acabamos de ver que não é tão simples assim, apenas com uma comparação de três visões diferentes sobre o tema da inclusão. Portanto, podemos utilizar a definição de inclusão digital como

um processo que deve levar o indivíduo à aprendizagem no uso das TICs e ao acesso à informação disponível nas redes, especialmente aquela que fará diferença para a sua vida e para a comunidade na qual está inserido (SILVA et al., 2005, p.32). 
Sendo assim, temos uma perspectiva essencialmente calcada na visão de ética universal, de acordo com a essência de nosso tempo, em que a inclusão digital:

$$
\begin{aligned}
& \text { deve ser vista sob o ponto de vista ético, sendo considerada } \\
& \text { como uma ação que promoverá a conquista da "cidadania } \\
& \text { digital" e contribuirá para uma sociedade mais igualitária, com a } \\
& \text { expectativa da inclusão social (SILVA et al., 2005, p. 30). }
\end{aligned}
$$

Dessa forma, podemos finalizar essa idéia com um novo conceito de cidadania. Segundo Silva citando Frade, em que um novo modelo deve ir além da esfera da informação:

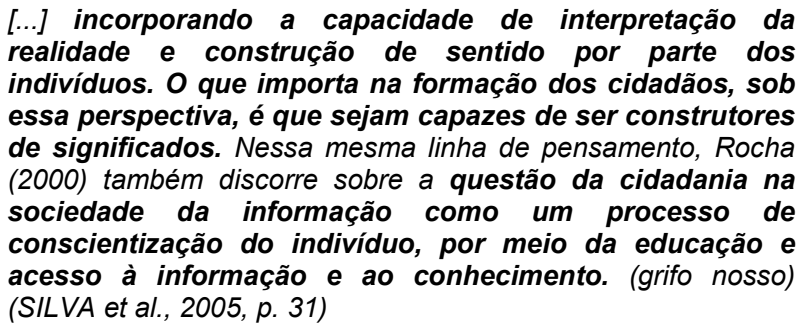

[...] incorporando a capacidade de interpretação da realidade e construção de sentido por parte dos indivíduos. $O$ que importa na formação dos cidadãos, sob essa perspectiva, é que sejam capazes de ser construtores de significados. Nessa mesma linha de pensamento, Rocha (2000) também discorre sobre a questão da cidadania na sociedade da informação como um processo de conscientização do indivíduo, por meio da educação acesso à informação e ao conhecimento. (grifo nosso) (SILVA et al., 2005, p. 31)

Os conceitos estudados e difundidos são muitos. O importante é que temos disponível uma gama de idéias enriquecedoras em nível social, bastando uni-las em prol de algo maior, uma confluência de conceitos que, juntos, produzem um mais completo, fazendo jus à complexidade da temática estudada.

\section{Apropriação social da Tecnologia}

O conceito de apropriação social da ciência e tecnologia é um dos mais importantes para esse artigo, pois é com ele que adquirimos a capacidade de traduzir o processo de apreensão e "ressignificação" de informação por parte das pessoas em seus mínimos detalhes, culminando com o que chamamos de apropriação social da tecnologia, que seria quando a pessoa atinge um estágio avançado de conhecimento das ferramentas e processos envolvidos, de forma a exercer um domínio científico e tecnológico ao ponto 
de ser capaz de usar esses novos conhecimentos para melhorias diretas em sua própria vida e também de outros (BUZATO, 2008).

Dessa forma, apropriação social torna-se um processo complexo de construção de significados unido a um domínio sobre determinado conhecimento científico e tecnológico, nesse caso, um domínio do uso das TICs de forma a obter consequências e benefícios sociais diretos.

Ainda, mais uma vez, encontramos problemas com o termo "incluir", como pudemos observar anteriormente com Buzato. Cabral Filho e Cabral nos trazem uma contribuição sobre essa questão, utilizando como base um conceito de apropriação em que:

\begin{abstract}
Incluir é pressupor algo que se tem e se pretende passar para alguém. Apropriar-se, além de reconhecer co-participação, implica em [sic] conscientização a respeito das possibilidades e necessidades de uso. Trata-se, portanto, muito mais do que uma mudança de bandeira ou de foco, mas da afirmação de valores democratizantes num processo comunicacional na relação de indivíduos com as tecnologias, através da utilização de recursos e serviços, bem como de indivíduos e grupos entre si. (CABRAL FILHO e CABRAL, 2005, p. 12)
\end{abstract}

Para Alonso (2008) o significado do termo "apropriação" no dicionário nada mais é que "ação e efeito de apropriar", sendo que isso pode se desdobrar em duas situações. Na primeira, alguém passa a ter algo que não Ihe pertencia anteriormente. Na segunda, temos uma ideia de adequação de algo a alguma coisa. Alonso (2008) tenta trabalhar o conceito de apropriação social da ciência baseando-se nessa segunda possibilidade que, para ele, potencializa o significado de apropriação.

Dessa forma, Alonso trata a apropriação social como uma questão de redistribuição de conhecimento, da seguinte maneira:

\footnotetext{
Mientras que la primera acepción conduce a plantear e intentar resolver el problema de la transmisión del conocimiento científico y técnico de quienes lo poseen a los que no, la segunda conduce a replantearlo como un problema de redistribución del conocimiento, redefiniendo el papel de los actores implicados y disolviendo la brecha aparente entre el sistema de ciencia y tecnología y el resto de la sociedad. (ALONSO, 2008, p. 214)
}

Continuando sua reflexão Alonso (2008) ainda nos traz uma outra perspectiva, que é de participação igualitária em processos de construção 
de conhecimento por intermédio de um processo anterior de apropriação social da ciência e tecnologia. Por exemplo, uma apropriação efetiva pode elevar um usuário comum de TICs a um grau de igualdade e colaboração direta com cientistas da computação (produtores de software).

\begin{abstract}
Romper la dialéctica aficionados/profesionales: el trabajo de los aficionados puede, em determinados casos y condiciones, ser comparable al de los profesionales. La división entre unos y otros se difumina, en paralelo con la de trabajo remunerado/trabajo voluntario (ALONSO, 2008, p. 222).
\end{abstract}

Nesse caso, um exemplo é aquilo que Alonso (2008) chama de desarrollo cooperativo, ou desenvolvimento cooperativo/colaborativo, como no caso da produção de software de código aberto.

\title{
O programa Gesac
}

O Governo Eletrônico - Serviço de Atendimento ao Cidadão é um programa de inclusão digital em larga escala do governo federal, diretamente vinculado ao Ministério das Comunicações.

As informações sobre o Gesac foram coletadas em documentos oficiais do Ministério das Comunicações, Secretaria de Telecomunicações, Departamento de Serviços de Inclusão Digital, responsável por esse serviço.

O Gesac "tem como meta disponibilizar acesso à Internet e mais um conjunto de outros serviços de inclusão digital a comunidades excluídas do acesso e dos serviços vinculados à rede mundial de computadores" (ID BRASIL, 2009a). Dentre esses serviços, estão os de governo eletrônico, em que os cidadãos participam de uma interface direta entre governo e população no que diz respeito à transparência de informações, serviços úteis à cidadania, aprimoramento da gestão, bem como serviços que, simplesmente facilitam a vida do cidadão, como consulta e pagamento online de multas de trânsito, consulta cadastral na Receita Federal, dentre outros. 
O GESAC objetiva também promover a inclusão digital como alavanca para o desenvolvimento social auto-sustentável e a promoção da cidadania, estando destinado prioritariamente às camadas $C, D$ e $E$ e às áreas sem infra-estrutura (rurais e remotas) da sociedade. (BARBOSA, 2008, p. ???)

Os Pontos de Presença do programa Gesac, como são chamados, privilegiam áreas remotas, com dificuldades de acesso e, até mesmo, aquelas sem nenhum tipo de infraestrutura de comunicações. Um dos maiores exemplos é o programa de telemedicina atendido pelo Ponto de Presença do Gesac no meio da selva amazônica, em que os pacientes de municípios afastados desfrutam de um atendimento guiado, em que um clínico geral ao lado do paciente comunica-se com especialistas de diversas áreas da medicina por vídeoconferência, podendo o especialista estar em qualquer parte do mundo.

O programa visa implantar, além da infraestrutura, programas de capacitação, cursos, eventos interativos e todo tipo de ação de promoção da cidadania, permitindo que pessoas divulguem e preservem culturas tradicionais, informem-se e participem cada vez mais, comuniquem-se por meio de ferramentas digitais específicas fornecidas pelo próprio programa Gesac. O projeto tem influência direta no âmbito da inclusão social, principalmente por ser o principal programa de inclusão digital do governo brasileiro.

Outra vertente de ação, não só do Gesac, mas de todos os programas de inclusão governamentais, é promover uma integração desses programas com a expansão do governo eletrônico no Brasil. Sobre governo eletrônico, temos que:

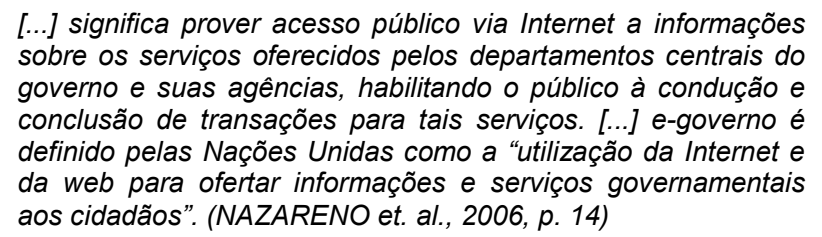

Existem muitas outras definições para governo eletrônico, e-gov ou ainda e-governo, como: 
O governo eletrônico, ou e-governo, é uma concepção que assimila os potenciais da TICs na transformação da administração pública, com substancial melhoria da sua organização, dos seus serviços e do relacionamento com a sociedade. (KNIGHT, CAMPOS e FERNANDES, 2006, p. 16)

O Programa Gesac (2008) ainda conta com dois portais para veiculação de conteúdo. Um deles, o www.idbrasil.gov.br, hospeda os conteúdos provenientes de comunicação oficial por parte do governo, enquanto que o outro, o www.idbrasil.org.br, é utilizado como espaço de interatividade entre os usuários do projeto, um local em que as pessoas podem expressar-se das mais variadas formas, contando com uma gama de ferramentas digitais de gestão de conhecimento e de conteúdo disponibilizadas pelo próprio programa".

A utilização de software livre é a base do Gesac, assim como em muitos outros programas governamentais. Segundo o portal oficial do Gesac,

\begin{abstract}
O Programa GESAC tem como premissa o incentivo do uso de softwares (inclusive aplicativos) e sistemas operacionais cujas licenças permitam livremente a execução, estudo, alteração, cópia e distribuição do produto, sem restrições, impedimentos ou ônus de quaisquer espécies. Toda a plataforma multiserviços [sic] para Inclusão Digital foi desenvolvida em software livre, incluindo sistemas operacionais LINUX, serviços de rede, aplicativos e serviços de segurança e de gerenciamento (ID BRASIL, 2009b, .
\end{abstract}

Hoje, uma das maiores representatividades do software livre é a inclusão digital. Tanto em projetos públicos quanto privados, o software livre é fortemente utilizado na estruturação e na execução de programas desse tipo, auxiliando de várias formas, operacional e financeiramente. Além disso, esse tipo de software propicia uma alternativa extremamente importante, pois dão margem para que sejam modificados e adaptados para as necessidades específicas do público desejado.

A posição ideológica do programa Gesac é a de que Inclusão digital é sinônimo de software livre, como pode ser observado no site oficial do projeto: 
Plano de Inclusão Digital e Alfabetização Tecnológica aprofunda a visão da educação entendida como prática socia transformadora da sociedade. [...] Por isso, o uso do software livre é uma decisão política-educacional (ID BRASIL, 2009b).

\section{Experiências no Gesac}

A dificuldade de consultar um médico no meio da floresta amazônica era um verdadeiro transtorno, pois muitas vezes este profissional não estava disponivel no hospital mais próximo. Essa situação foi amenizada com a implantação de um ponto de Internet via satélite em um hospital da região, com computador e câmera de vídeo, permitindo que um clínico-geral fosse guiado por um especialista em qualquer parte do mundo em consultas médicas e até mesmo em determinados procedimentos cirúrgicos. É a Telemedicina, que teve seu primeiro ponto instalado no município de São Gabriel da Cachoeira, que fica a 860 quilômetros de Manaus (AM).

Além da saúde, setores sociais são extremamente beneficiados por iniciativas vindas do Gesac. As grandes experiências de interconexão de comunidades, com divulgação e perpetuação de tradições, expansão de atividades comerciais e consolidação de redes de comunicação de forma mais ampla, foram observadas com povos indígenas e comunidades quilombolas, gerando inovações como o Indiosonline ${ }^{1}$ (2009) e a Rede Mocambos ${ }^{2}$.

Por intermédio de projetos implementados com a infraestrutura Gesac, diversos povos indígenas se uniram em uma rede de comunicação online com vistas a divulgarem sua cultura, seus produtos e perpetuarem suas tradições, além de reafirmarem sua posição na sociedade sem que para isso tenham de largar suas origens. Algo similar acontece com comunidades quilombolas de várias partes do Brasil.

\footnotetext{
Um grande encontro virtual de nações indígenas, http://www.indiosonline.org.br.

"É uma rede de comunidades quilombolas, indígenas, urbanas, rurais, associações da sociedade civil, pontos de cultura, oriundos de norte ao sul do país, conectados através das tecnologias da informação e comunicação". Disponível em <<http://www.mocambos.net/>>. Acesso em: 19 ago. 2009.
} 
O Gesac já prestou serviços em que conectou comunidades isoladas, ajudando-as inclusive em sua sobrevivência e reintegração social, como aconteceu com a Aldeia Indígena Kuikuro, situada no Alto Xingú, na cidade de Gaúcha do Norte no Mato Grosso, onde os índios vivenciam a produção de vídeos e registros cinematográficos de sua própria cultura, sendo inseridos em uma nova forma de perpetuação de seus costumes. Em Olinda, Pernambuco, o sinal Gesac conectou quatro comunidades quilombolas urbanas à Rede Mocambos, ajudando-as a manterem contato entre elas e também com outras comunidades de outras localidades.

$\mathrm{Na}$ Casa Brasil do Moinho Cultural Sul-Americano, situada em Corumbá, no Mato Grosso do Sul, existe um Estúdio Multimídia onde ocorrem oficinas de manipulação de áudio, de vídeo e de fotografia digital. A casa conta ainda com oficinas de Astro-lábio digital e criação de Blogs, uma sala de leitura com atividades como criação de histórias em quadrinhos, Origami, Griô, contador de histórias e sarau de poesia, além de um laboratório de ciências onde grupos de teatro são formados para apresentarem trabalhos científicos na comunidade. Dessa forma, inúmeras possibilidades são passadas para os usuários.

Os casos são muitos, em escolas, bases militares, missões marítimas e muito mais. Além da infraestrutura, o Gesac promove inúmeras atividades diferenciadas, culturais, musicais, teatrais, sempre tentando demonstrar para as pessoas a infinidade de possibilidades com que as TICs podem ser utilizadas no processo de inserção e reafirmação social.

\section{Considerações finais}

Os processos de inclusão digital devem ter como objetivo principal a cidadania digital e inclusão social, necessitando para isso de uma apropriação social efetiva das TICs, além de um pensamento diferenciado para a essência dos projetos, tendo sempre em vista uma questão de ética e cidadania, com modelos pedagógicos que auxiliem os indivíduos em suas construções próprias, individuais e comunitárias de significados. 
Por intermédio das informações passadas e das experiências concretas do programa Gesac apresentadas, vimos que ele ocupa um lugar de peso nas iniciativas atuais no campo da inclusão digital. Segundo informações do coordenador de Projetos Especiais do Ministério das Comunicações, Carlos Paiva, divulgadas no portal oficial do Gesac,

\begin{abstract}
até 30 de outubro, o ministério já havia entregado 5.890 telecentros. Desses, 5.409 já foram montados e 5.261 já contam com conexão gratuita à internet de alta velocidade. Nessa primeira fase de implantação do programa, o ministério investiu cerca de $R \$ 134$ milhões. "É um programa pioneiro e considerado um dos maiores êxitos de inclusão digital em larga escala na América Latina", disse. (PROENÇA, 2009)
\end{abstract}

O programa Gesac tem surpreendido a todos com uma extensa promoção de aumento do acesso às TICs, bem como uma série de experiências concretas e bem-sucedidas de exercício de cidadania. Em entrevista veiculada no portal Gesac, em 2003, bem no início das atividades do projeto, Cristovam Buarque, quando ainda era ministro da educação, já acreditava no potencial do Gesac

O programa, na forma como foi implementado na parceira MC/MEC, é o mais ousado programa de inclusão digital já realizado nesse país. Veja bem, nesses meses, aumentamos em mais de $20 \%$ o total de escolas conectadas à internet. (ID BRASIL, 2004d)

Sem dúvida, o Gesac trouxe inúmeros ganhos às comunidades atingidas por este programa de inclusão e cidadania, mas as atividades não podem parar, pois, apesar de tudo, o Brasil é imenso e ainda existe uma série de regiões desconectadas. Sendo assim, o programa ainda tem muito que expandir e muitos para conectar. Para terminar este artigo, deixamos uma frase extraída do vídeo oficial do Gesac, bem cativante e ilustrativa de tudo aquilo de que tratamos aqui:

O Gesac é um programa de programas, é um canal para integrar diversas ações, socializar iniciativas e buscar a melhora da qualidade de vida das pessoas em suas cidades. $O$ Gesac não dá computadores, não paga monitores, não constrói telecentros, nem garante manutenção. Mas cria condições e incentivo para que o convívio social floresça, outras formas de pensar sejam conhecidas, debatidas e respeitadas; e possamos repensar nossa sociedade e o futuro de nosso 


\section{Referências}

ALONSO, C. B. La apropiación social de la ciencia: nuevas formas. Revista CTS, v. 4, n. 10, p. 213-225, 2008 . Disponível em: <http://www.revistacts.net/4/10/014/file>. Acesso em: 11 mar. 2009.

BARBOSA, A. F. Os caminhos para o avanço do governo eletrônico no Brasil. In: CGI.br (Comitê Gestor da Internet no Brasil). Pesquisa sobre o uso das tecnologias da informação e da comunicação 2008. São Paulo, 2009. p. 67-71. Disponível em: <http://www.cgi.br/publicacoes/artigos/artigo63.htm>. Acesso em 20 de agosto de 2009.

BUZATO, M. El K. Inclusão digital como invenção do quotidiano: um estudo de caso. Revista Brasileira de Educação, v. 13, n. 38, maio/ago. 2008.

CABRAL FILHO, A. V.; CABRAL, E. D. T. A contribuição da apropriação social das tics para viabilizar uma lei de comunicação social democrática no Brasil. In: V ENLEPICC - Encontro latino de economia política da informação, comunicação e cultura, Faculdade Social da Bahia, Salvador, 5, p. 9-11, nov. 2005.

CARVALHO, A. M. G.; CARVALHO, J. M. Alfabetização Digital: Análise do GESAC e da construção da cidadania nas redes de informação e comunicação. In: XVII ENDOCOM - Encontro de Informação em Ciências da Comunicação, XXX Congresso Brasileiro de Ciências da Comunicação, Santos, 2007.

CASA BRASIL. O que é o Casa Brasil. 30 de maio de 2008. Disponível em: <http://www.casabrasil.gov.br/index.php?option=com_content\&task=view\&id =275\&Itemid=74>. Acesso em: 20 ago. 2008 .

ID BRASIL. 2009a. Disponível em: <http://www.idbrasil.gov.br/>. Acesso: 20 ago. 2009.

ID BRASIL. Inclusão digital é sinônimo de software livre. 2009b. Disponível em: <http://www.idbrasil.gov.br/docs_telecentro/docs_telecentro/sw_livre>. Acesso em: 20 ago. 2009.

ID BRASIL. Recursos Multimídia. Vídeo sobre o Programa GESAC. 2009c. Disponível em: <http://www.idbrasil.gov.br/docs_prog_gesac/recursos_multimidia>. Acesso em: 20 ago. 2009. 
ID BRASIL. Ministro da Educação descreve a importância do Programa Gesac. 2009d. Disponível em: < http://www.idbrasil.gov.br/docs_prog_gesac/artigos_entrevistas/entrevista_c ristovao>. Acesso em: 08 jan. 2010.

INDIOSONLINE. 2009. Disponível em: <http://www.indiosonline.org.br/novo/>. Acesso em: 19 ago. 2009.

KNIGHT, P. T.; CAMPOS, C.; FERNANDES, C. F. (Orgs.). e-Brasil: um programa para acelerar o desenvolvimento socioeconômico aproveitando a convergência digital. São Caetano do Sul, SP: Yendis Editora, 2006.

NAZARENO, C.; BOCCHINO, E.V.; MENDES, F. L.; PAZ FILHO, J. de S. Tecnologias da informação e sociedade: o panorama brasileiro. Brasília: Câmara dos Deputados, Coordenação de Publicações, 2006.

PORTAL DA REDE MOCAMBOS. Disponível em: <http://www.mocambos.net/>. Acesso em: 20 ago. 2009.

PROENÇA, Danyella. Ministério inicia testes com protótipo de equipamento para ampliar inclusão digital. Ascom/Ministério das Comunicações. Disponível em: http://www.mc.gov.br/ministerio-inicia-testescom-prototipo-de-equipamento-para-ampliar-inclusao-digital/. Acesso: 17 jan. 2010.

PROGRAMA GESAC. Manual do Usuário do Programa GESAC: Governo Eletrônico Serviço de Atendimento ao Cidadão/Ministério das Comunicações, Secretaria de Telecomunicações, Departamento de Serviços de Inclusão Digital. 4. ed. Brasília: Ministério das Comunicações, 2008.

REVISTA DO MINISTÉRIO DAS COMUNICAÇÕES: Ministério Das Comunicações, Brasília-DF, n. 2, dez. 2008. Disponível em: <http://www.mc.gov.br/projetos/revista-do-ministerio/revista-ministeriocomunicacoes-web-2.pdf/at_download/file>. Acesso em: 19 ago. 2009.

SILVA, H.; JAMBEIRO, O.; LIMA, J.; BRANDÃO, M. A. Inclusão digital e educação para a competência informacional: uma questão de ética e cidadania. Ci. Inf., v. 34, n. 1, jan./abr. 2005, p. 28-36. Disponível em: <http://www.scielo.br/pdf/ci/v34n1/a04v34n1.pdf>. Acesso: jul. 2009.

TAKAHASHI, T. (Org.). Sociedade da Informação no Brasil: Livro Verde. Brasília: Ministério da Ciência e Tecnologia, 2000. 